\title{
Qualidade das sementes de soja após a colheita com dois tipos de colhedora e dois períodos de armazenamento
}

\author{
Soybean seed quality after harvesting with two types of harvester and two storage times
}

\author{
João Paulo Arantes Rodrigues da Cunha' Pablo de Oliveira' ${ }^{\text {II }}$ Carlos Machado dos Santos ${ }^{\text {II }}$ \\ Renildo Luiz Mion"II
}

\section{RESUMO}

A colheita mecanizada de soja pode acarretar perdas qualitativas nas sementes. O presente trabalho teve como objetivo avaliar a qualidade de sementes de soja colhidas mecanicamente por sistemas axial e tangencial de trilha, em diferentes velocidades de avanço da colhedora, antes e após o período de armazenamento de seis meses. Utilizou-se o delineamento experimental de blocos casualizados, em esquema de parcela subdividida no tempo, com quatro repetições. Nas parcelas, foram avaliados os procedimentos de colheita e, nas subparcelas, as épocas de avaliação da qualidade da semente. Os procedimentos de colheita foram: colhedora com sistema de trilha axial, deslocando-se a 6, 8 e $10 \mathrm{~km} \mathrm{~h}^{-1}$, colhedora com sistema de trilha tangencial (convencional), deslocando-se a 4 e $6 \mathrm{~km} \mathrm{~h}^{-1}$, e colheita manual. Foram analisadas as seguintes variáveis: germinação, porcentagem de plântulas fortes, índice de velocidade de emergência (IVE), emergência em areia e injúria mecânica. Pôde-se concluir que o emprego das colhedoras com sistemas de trilha tangencial e axial não provocou diferenças no índice de velocidade de emergência, no vigor e na germinação das sementes de soja. No entanto, com relação à injúria mecânica, a colhedora axial mostrou-se superior à convencional. $O$ incremento da velocidade de deslocamento, dentro dos parâmetros recomendados pelo fabricante, não alterou a qualidade das sementes. O armazenamento reduziu o vigor das sementes colhidas.

Palavras-chave: Glycine $\boldsymbol{m a x}$ (L.)Merrill, dano mecânico, sistema de trilha, colheita mecanizada.

\section{ABSTRACT}

Soybean mechanical harvest may bring qualitative losses to seeds. This study aimed to evaluate the quality of soybean seeds mechanically harvested by axial and conventional threshing systems, at different displacement speeds of the harvesters, before and after the storage period of six months. A randomized complete block design in a split-plot arrangement with four replications was used. The main plots were the harvest systems and the split-plots were the storage times. The harvest systems were: axial flow harvester, at 6, 8 and $10 \mathrm{~km} \mathrm{~h}^{-1}$, conventional harvester, at 4 and $6 \mathrm{~km} \mathrm{~h}^{-1}$, and manual harvest. Germination, percentage of normal seedlings, emergency speed index, sand emergency and mechanical damage of soybean seeds were evaluated. The results showed that the use of axial flow and conventional harvesters did not affect the emergency speed index, vigor and germination of soybean seeds. However, the axial flow system provided less mechanical damage. The increase of displacement speed, within the ranges of the operating parameters recommended by the manufacturer, did not change seed quality. Storage reduced seed vigor.

Key words: Glycine $\max ($ L.) Merrill, mechanical damage, threshing system, mechanized harvest.

\section{INTRODUÇÃO}

A crescente modernização da sojicultura brasileira tem exigido dos diferentes segmentos, dentre eles os produtores de sementes, mudanças profundas para aperfeiçoar o processo produtivo. No sistema de produção que visa à otimização de padrões quantitativos e qualitativos, a semente de alta qualidade ocupa papel fundamental (COSTA et al., 2001).

IInstituto de Ciências Agrárias, Universidade Federal de Uberlândia (UFU), 38400-902, Uberlândia, MG, Brasil. E-mail: jpcunha@iciag.ufu.br. Autor para correspondência.

IIInstituto de Ciências Agrárias, UFU, Uberlândia, MG, Brasil.

IIIDepartamento de Engenharia Agrícola, Universidade Federal do Ceará (UFC), Fortaleza, CE, Brasil. 
Durante a colheita, no momento da trilha, a semente fica suscetível ao dano mecânico (imediato ou latente). A ação de trilha realizada entre o cilindro e o côncavo envolve operações simultâneas de impacto, compressão e atrito, que podem danificar estruturas essenciais das sementes, aumentar a suscetibilidade a microrganismos e a sensibilidade a fungicidas e reduzir o vigor e a germinação (PAIVA et al., 2000).

Os danos mecânicos ocorrem, sobretudo, devido a regulagens não adequadas das máquinas que realizam a operação de colheita e beneficiamento das sementes, principalmente, quando estas apresentam umidade inadequada. Esses danos podem atingir diferentes partes da semente, podendo comprometer totalmente um determinado lote (BASRA, 1994). Sementes colhidas com teor de água abaixo de $11 \%$ estão suscetíveis ao dano mecânico imediato, enquanto que aquelas colhidas com teor superior a $15 \%$ estão sujeitas a maior incidência de danos mecânicos latentes (EMBRAPA, 2005).

Para a colheita mecânica da soja, existem no mercado as colhedoras com sistema de trilha tangencial, constituído de cilindro e côncavo transversais, também conhecidas como convencionais ou radiais, e as colhedoras de fluxo axial, cujo rotor e côncavo, em geral, encontram-se posicionados longitudinalmente à máquina. Ambas podem produzir efeitos diferenciados na qualidade fisiológica do material a ser utilizado como semente (MARCONDES et al., 2005).

Durante a colheita, normalmente o que se espera de um mecanismo de trilha é a redução das perdas de sementes e a minimização dos danos mecânicos transmitidos a elas (COSTA et al., 2005). No sistema de trilha convencional, há menor tempo de permanência do material na seção de trilha e, por conseqüência, impactos mais agressivos. Já no sistema de trilha axial, o material a ser trilhado se desloca na direção paralela ao eixo do cilindro de trilha, normalmente denominado de rotor, com maior tempo para a separação.

Segundo COSTA et al. (2003), o sistema de trilha tangencial tende a promover mais danos às sementes. Entretanto, MARCONDES et al. (2005) explicam que, tanto a colhedora de cilindro tangencial, quanto a axial, desde que convenientemente utilizadas na colheita em relação às especificações de regulagem, não provocam diferenças na qualidade da semente de soja.

Mesmo com as informações disponíveis, ainda há dúvidas, sendo necessárias mais informações quanto à eficiência de colhedoras envolvendo diferentes sistemas de trilha e períodos de armazenamento, visando obter sementes de melhor qualidade. O armazenamento também é variável importante que pode influenciar a qualidade das sementes, principalmente em função de danos latentes.

O presente trabalho teve como objetivo avaliar a qualidade de sementes de soja colhidas mecanicamente por sistemas axial e tangencial de trilha, em diferentes velocidades de avanço da colhedora, antes e após o período de armazenamento de seis meses.

\section{MATERIAL E MÉTODOS}

Este trabalho foi realizado na Fazenda JC Aroeira, localizada no município de Nova Ponte, Minas Gerais (MG), e no Laboratório de Sementes da Universidade Federal de Uberlândia. As amostras de sementes de soja (Glycine $\boldsymbol{m a x}$ (L.)Merrill), cultivar 'Monsoy 8329', foram coletadas por ocasião da colheita da lavoura, semeada com espaçamento entre linhas de 0,45m e 11 plantas por metro. A umidade média das amostras no ato da colheita foi de $11,5 \%$.

A coleta do material no campo foi feita no mês de abril, durante o ano agrícola 2006/2007, e as amostras foram submetidas às análises laboratoriais, nos meses de maio e novembro de 2007, constituindo a Fase 1 e a Fase 2, respectivamente. Durante esse período, as sementes foram armazenadas em câmara fria, sob temperatura de $12^{\circ} \mathrm{C}$ e umidade relativa de $65 \%$. A avaliação, realizada após a armazenagem, teve como objetivo verificar possíveis danos latentes, simulando a armazenagem da semente que ocorre no campo antes da semeadura.

Foram avaliadas duas colhedoras autopropelidas, sendo uma John Deere STS 9750, com sistema de trilha axial, motor de $242 \mathrm{~kW}$, ano 2005 e plataforma de 25 pés $(7,62 \mathrm{~m})$, e outra John Deere 1185 , com sistema de trilha tangencial (convencional), motor de $132 \mathrm{~kW}$, ano 2000 e plataforma de 19 pés $(5,79 \mathrm{~m})$.

Utilizou-se o delineamento experimental de blocos casualizados, em esquema de parcelas subdivididas no tempo, com quatro repetições. Nas parcelas, foram avaliados os procedimentos de colheita e, nas subparcelas, as épocas de avaliação da qualidade da semente (sementes recém-colhidas e após seis meses de armazenamento). Os procedimentos de colheita foram: colhedora com sistema de trilha axial, deslocando-se a 6 , 8 e $10 \mathrm{~km} \mathrm{~h}^{-1}$, colhedora com sistema de trilha tangencial (convencional), deslocando-se a 4 e a $6 \mathrm{~km} \mathrm{~h}^{-1}$, e colheita manual.

A colhedora axial, para a velocidade de $6 \mathrm{~km}$ $\mathrm{h}^{-1}$, trabalhou com rotação do cilindro a 310rpm e abertura do côncavo de $18 \mathrm{~mm}$. Na velocidade de $8 \mathrm{~km}$ $\mathrm{h}^{-1}$, a rotação do cilindro foi de 320rpm e a abertura do 
côncavo foi de $15 \mathrm{~mm}$. Na velocidade de $10 \mathrm{~km} \mathrm{~h}^{-1}$, a colhedora axial trabalhou com rotação do cilindro de 390rpm e abertura do côncavo de $11 \mathrm{~mm}$. A colhedora tangencial (convencional), para a velocidade de $4 \mathrm{~km} \mathrm{~h}^{-1}$, trabalhou com a rotação do cilindro a 540rpm e a abertura do côncavo na posição 30 , com $3,5 \mathrm{~cm}$ na parte da frente e $6 \mathrm{~cm}$ na parte de trás. Na velocidade de $6 \mathrm{~km}$ $\mathrm{h}^{-1}$, a rotação do cilindro foi de 550rpm e a abertura do côncavo foi mantida a mesma.

A coleta das sementes foi realizada diretamente na rosca sem fim que abastece o tanque graneleiro das colhedoras, depois de estabilizada a alimentação. Após coletadas, as amostras foram conduzidas ao laboratório, onde foram submetidas à limpeza utilizando-se as peneiras 10 e 13 (crivo redondo), sendo descartadas as impurezas. Em seguida, as sementes foram submetidas à passagem pelo homogeneizador (Modelo Borne). Posteriormente, foram analisadas as seguintes variáveis: injúria mecânica, teste de germinação, porcentagem de plântulas normais fortes, índice de velocidade de emergência (IVE) e emergência em areia.

No teste de injúria mecânica, foram utilizadas duas subamostras de 100 sementes por parcela, colocadas para serem embebidas em copos plásticos de $200 \mathrm{~mL}$, cobrindo-as com solução de hipoclorito de sódio (5\%), por 10 minutos, à temperatura ambiente. A seguir, a solução foi drenada e, então, avaliou-se o número de sementes com danos, segundo critério estabelecido por VAUGHAN (1982).

Com relação aos testes de germinação e vigor, estes foram conduzidos com quatro subamostras de 50 sementes, por parcela, semeadas entre duas folhas de papel germitest, umedecidas com água deionizada, com volume de água, em mililitros, correspondente a duas vezes e meia a massa do papel seco, em gramas. Foram confeccionados rolos, que foram colocados em germinador, regulado à temperatura de $25^{\circ} \mathrm{C}$, de acordo com as Regras de Análise de Sementes (BRASIL, 1992). A avaliação foi realizada aos cinco dias após a montagem do teste, computando-se a porcentagem de plântulas normais, anormais danificadas e infeccionadas e sementes mortas. As plântulas normais foram classificadas em fortes e fracas, e a porcentagem de plântulas fortes correspondeu ao vigor e a porcentagem de plântulas normais total à germinação.

A determinação do índice de velocidade de emergência (IVE) e emergência em areia foi feita em casa-de-vegetação, utilizando bandejas plásticas, com dimensões de $55 \mathrm{~cm}$ de comprimento, $35 \mathrm{~cm}$ de largura e $9 \mathrm{~cm}$ de profundidade, contendo areia como substrato, a qual foi irrigada tendo como parâmetro $70 \%$ de sua capacidade de retenção de água. A areia foi previamente fumigada com brometo de metila, na dose de 20 mililitros para cada metro cúbico de areia. Foram semeadas 200 sementes por parcela, subdivididas em oito linhas com 25 sementes. Utilizaram-se gabaritos para a marcação das linhas e também para homogeneização da profundidade de semeadura. O critério utilizado para a contagem foi a emergência dos cotilédones acima da superfície da areia, e a contagem foi feita diariamente sempre no mesmo horário, de acordo com MAGUIRE (1962).

As análises estatísticas dos dados foram realizadas por meio de análise de variância, comparando-se as médias pelo Teste de Tukey, a 5\% de probabilidade, utilizando-se o programa Sisvar (Versão 4.3). Os resultados, expressos em percentagem, foram previamente transformados em arco seno da raiz quadrada de $(x+0,5) / 100$, para garantir normalidade $e$ homogeneidade das variâncias.

\section{RESULTADOS E DISCUSSÃO}

Na tabela 1, são apresentados os dados de injúria mecânica. Nota-se que não houve diferença significativa entre as Fases 1 e 2, indicando que o período de armazenamento não influenciou essa variável. Entretanto, comparando-se as formas de colheita entre si, nota-se que o tratamento correspondente à colheita manual foi o que apresentou menor porcentagem de injúria, como esperado. A colhedora axial, nas velocidades de 6 e $8 \mathrm{~km} \mathrm{~h}^{-1}$, mostrou-se superior à convencional. $\mathrm{O}$ incremento da velocidade não alterou o índice de injúria mecânica nas colhedoras axial e convencional.

Esses resultados estão de acordo com o proposto por VEJASIT \& SALOKHE (2004). As

Tabela 1 - Injúria mecânica em sementes de soja colhidas por diferentes sistemas avaliados, antes (Fase 1) e após (Fase 2) seis meses de armazenamento.

\begin{tabular}{lccc}
\hline & \multicolumn{3}{c}{ Injúria mecânica (\%) } \\
Procedimento de colheita & Fase 1 & Fase 2 & Média \\
\hline Colhedora axial a $6 \mathrm{~km} \mathrm{~h}^{-1}$ & 7,42 & 6,63 & $7,03 \mathrm{c}$ \\
Colhedora axial a $8 \mathrm{~km} \mathrm{~h}^{-1}$ & 5,67 & 5,88 & $5,78 \mathrm{c}$ \\
Colhedora axial a $10 \mathrm{~km} \mathrm{~h}^{-1}$ & 8,42 & 7,38 & $7,90 \mathrm{bc}$ \\
Colhedora convencional a $4 \mathrm{~km} \mathrm{~h}^{-1}$ & 10,83 & 10,36 & $10,60 \mathrm{ab}$ \\
Colhedora convencional a $6 \mathrm{~km} \mathrm{~h}^{-1}$ & 12,58 & 13,00 & $12,79 \mathrm{a}$ \\
Colheita manual & 2,25 & 0,50 & $1,38 \mathrm{~d}$ \\
Média & $7,86 \mathrm{~A}$ & $7,29 \mathrm{~A}$ & \\
CV (\%) parcela & \multicolumn{3}{c}{10,02} \\
CV (\%) subparcela & 12,33 & \\
\hline
\end{tabular}

* Médias seguidas por letras distintas maiúsculas, nas linhas, e minúsculas, nas colunas, diferem significativamente entre si, a 5\% de probabilidade pelo teste de Tukey. 
colhedoras com sistema de trilha axial, em que o material entra no sentido do eixo do rotor, apresentam maior capacidade de colheita e permitem a redução dos índices de danos mecânicos em relação às colhedoras com sistema de trilha com alimentação tangencial. Como o tempo para a trilha no sistema axial é maior, a distância entre os elementos de fricção pode ser aumentada, resultando, em geral, em menor dano às sementes, como pôde ser observado na comparação entre a colhedora axial, a 6 e $8 \mathrm{~km} \mathrm{~h}^{-1}$, e a convencional, a $6 \mathrm{~km} \mathrm{~h}^{-1}$.

Para o índice de velocidade de emergência (Tabela 2), nota-se que a interação entre a forma de colheita e as fases de avaliação não foi significativa, mostrando a independência dos dois fatores. Quanto à forma de colheita, não houve diferença significativa entre os tratamentos, concordando com os dados encontrados por VIEIRA et al. (2006), em que o índice de velocidade de germinação não foi influenciado pelos fatores velocidade e rotação do cilindro de trilha. No entanto, a comparação dos dados entre as Fases 1 e 2 indica que houve diferença, sendo o IVE maior na Fase 2. Esperava-se, no entanto, que, se houvesse diferença estatística significativa, esta apontaria um IVE maior na Fase 1 das análises.

Tal fato pode ser explicado pela influência do ambiente no qual foram realizadas as análises. Durante a Fase 1, a temperatura média na casa-devegetação, durante o período avaliado, medida às 15 horas, foi de $31^{\circ} \mathrm{C}$, enquanto que, durante a Fase 2, foi de $38^{\circ} \mathrm{C}$. Esse aquecimento, promovido pelas épocas de análise, provavelmente contribuiu para acelerar a germinação na Fase 2, sendo tal fato intrínseco às

Tabela 2 - Índice de velocidade de emergência de sementes de soja colhidas por diferentes sistemas avaliados, antes (Fase 1) e após (Fase 2) seis meses de armazenamento.

\begin{tabular}{|c|c|c|c|}
\hline \multirow{2}{*}{ Procedimento de colheita } & \multicolumn{3}{|c|}{$\begin{array}{l}\text { Índice de velocidade de } \\
\text { emergência (IVE) }\end{array}$} \\
\hline & Fase 1 & Fase 2 & Média \\
\hline Colhedora axial a $6 \mathrm{~km} \mathrm{~h}^{-1}$ & 65,00 & 81,86 & $73,43 a$ \\
\hline Colhedora axial a $8 \mathrm{~km} \mathrm{~h}^{-1}$ & 62,49 & 94,90 & $78,70 a$ \\
\hline Colhedora axial a $10 \mathrm{~km} \mathrm{~h}^{-1}$ & 63,76 & 87,73 & $75,75 a$ \\
\hline Colhedora convencional a $4 \mathrm{~km} \mathrm{~h}^{-1}$ & 57,88 & 88,47 & $73,18 \mathrm{a}$ \\
\hline Colhedora convencional a $6 \mathrm{~km} \mathrm{~h}^{-1}$ & 59,06 & 86,08 & $72,57 \mathrm{a}$ \\
\hline Colheita manual & 63,59 & 85,16 & $74,38 a$ \\
\hline Média & 61,96B & 87,37A & \\
\hline CV (\%) parcela & & 7,14 & \\
\hline CV (\%) subparcela & & 11,88 & \\
\hline
\end{tabular}

*Médias seguidas por letras distintas maiúsculas, nas linhas, e minúsculas, nas colunas, diferem significativamente entre si, a $5 \%$ de probabilidade pelo teste de Tukey. avaliações em casa-de-vegetação. Portanto, as avaliações nesses ambientes devem restringir-se às comparações entre tratamentos no mesmo período.

No que se refere à variável emergência em areia (Tabela 3), percebe-se que não houve diferença estatística entre os tratamentos analisados, ou seja, a velocidade de avanço, o período de armazenamento e o sistema de trilha não influenciaram a emergência em areia. O aumento da temperatura na casa-de-vegetação, na Fase 2, aumentou a velocidade de emergência, conforme destacado anteriormente. No entanto, esse aumento não afetou a porcentagem final de emergência.

Com relação à porcentagem de plântulas fortes (Tabela 4), os dados obtidos mostraram que houve diferença significativa entre as Fases 1 e 2 das análises, e, na Fase 1, o material analisado apresentou maior vigor quando comparado à Fase 2. Portanto, o armazenamento reduziu o vigor das sementes. COSTA et al. (2001) explicam que o tegumento da semente da soja pode ser facilmente danificado durante a colheita, colaborando para que a água e os microrganismos penetrem através das rachaduras ocasionadas por esse processo. Além disso, FRANÇA NETO \& HENNING (1984) afirmam que as partes embrionárias da semente de soja são protegidas por um tegumento pouco espesso, o que confere baixa proteção contra choques e abrasões observados durante a colheita mecanizada.

Não houve diferença significativa quando se compararam os procedimentos de colheita. Esses resultados estão de acordo com os obtidos por MARCONDES et al. (2005), que não encontraram diferenças estatísticas para o vigor entre colhedoras

Tabela 3 - Emergência em areia de sementes de soja colhidas por diferentes sistemas avaliados, antes (Fase 1) e após (Fase 2) seis meses de armazenamento.

\begin{tabular}{|c|c|c|c|}
\hline \multirow{2}{*}{ Procedimento de colheita } & \multicolumn{3}{|c|}{ Emergência em areia (\%) } \\
\hline & Fase 1 & Fase 2 & Média \\
\hline Colhedora axial a $6 \mathrm{~km} \mathrm{~h}^{-1}$ & 97,88 & 97,13 & $97,50 a$ \\
\hline Colhedora axial a $8 \mathrm{~km} \mathrm{~h}^{-1}$ & 97,38 & 97,50 & $97,44 a$ \\
\hline Colhedora axial a $10 \mathrm{~km} \mathrm{~h}^{-1}$ & 97,63 & 95,25 & $96,44 a$ \\
\hline Colhedora convencional a $4 \mathrm{~km} \mathrm{~h}^{-1}$ & 95,75 & 95,50 & $95,63 a$ \\
\hline Colhedora convencional a $6 \mathrm{~km} \mathrm{~h}^{-1}$ & 97,25 & 98,00 & $97,63 a$ \\
\hline Colheita manual & 99,38 & 98,38 & $98,88 a$ \\
\hline Média & $97,54 \mathrm{~A}$ & $96,96 \mathrm{~A}$ & \\
\hline CV (\%) parcela & & 1,68 & \\
\hline CV (\%) subparcela & & 1,56 & \\
\hline
\end{tabular}

*Médias seguidas por letras distintas maiúsculas, nas linhas, e minúsculas, nas colunas, diferem significativamente entre si, a 5\% de probabilidade pelo teste de Tukey. 
Tabela 4 - Porcentagem de plântulas fortes de sementes de soja colhidas por diferentes sistemas avaliados, antes (Fase 1) e após (Fase 2) seis meses de armazenamento.

\begin{tabular}{|c|c|c|c|}
\hline \multirow{2}{*}{ Procedimento de colheita } & \multicolumn{3}{|c|}{ \% plântulas fortes (vigor) } \\
\hline & Fase 1 & Fase 2 & Média \\
\hline Colhedora axial a $6 \mathrm{~km} \mathrm{~h}^{-1}$ & 87,50 & 81,00 & $84,25 a$ \\
\hline Colhedora axial a $8 \mathrm{~km} \mathrm{~h}^{-1}$ & 91,63 & 80,63 & $86,13 a$ \\
\hline Colhedora axial a $10 \mathrm{~km} \mathrm{~h}^{-1}$ & 88,25 & 82,75 & $85,50 a$ \\
\hline Colhedora convencional a $4 \mathrm{~km} \mathrm{~h}^{-1}$ & 84,75 & 83,38 & $84,07 \mathrm{a}$ \\
\hline Colhedora convencional a $6 \mathrm{~km} \mathrm{~h}^{-1}$ & 88,63 & 81,88 & $85,26 a$ \\
\hline Colheita manual & 90,88 & 85,25 & $88,07 \mathrm{a}$ \\
\hline Média & $88,61 \mathrm{~A}$ & $82,48 B$ & \\
\hline CV (\%) parcela & & 3,07 & \\
\hline CV (\%) subparcela & & 2,54 & \\
\hline
\end{tabular}

*Médias seguidas por letras distintas maiúsculas, nas linhas, e minúsculas, nas colunas, diferem significativamente entre si, a $5 \%$ de probabilidade pelo teste de Tukey.

axial e convencional. Por outro lado, COSTA et al. (1996), trabalhando com colhedoras com sistema de trilha radial, encontraram diferenças fisiológicas entre sementes de soja colhidas mecanicamente e manualmente, entretanto estas foram colhidas com 10,8\% de umidade. Esses autores também verificaram maior vigor de sementes colhidas em velocidade de deslocamento da colhedora de $4,5 \mathrm{~km} \mathrm{~h}^{-1}$ em relação à velocidade de $8,0 \mathrm{~km} \mathrm{~h}^{-1}$.

Para a variável germinação, a comparação dos dados obtidos mostrou que o período de armazenamento, o sistema de trilha e a velocidade de avanço não influenciaram o resultado final (Tabela 5). Houve ligeira tendência de redução da germinação com a colheita mecânica.

Tabela 5 - Germinação de sementes de soja colhidas por diferentes sistemas avaliados, antes (Fase 1) e após (Fase 2) seis meses de armazenamento.

\begin{tabular}{|c|c|c|c|}
\hline \multirow{2}{*}{ Procedimento de colheita } & \multicolumn{3}{|c|}{ Germinação (\%) } \\
\hline & Fase 1 & Fase 2 & Média \\
\hline Colhedora axial a $6 \mathrm{~km} \mathrm{~h}^{-1}$ & 94,13 & 95,00 & $94,57 a$ \\
\hline Colhedora axial a $8 \mathrm{~km} \mathrm{~h}^{-1}$ & 97,36 & 95,25 & $96,31 \mathrm{a}$ \\
\hline Colhedora axial a $10 \mathrm{~km} \mathrm{~h}^{-1}$ & 96,13 & 95,25 & $95,69 a$ \\
\hline Colhedora convencional a $4 \mathrm{~km} \mathrm{~h}^{-1}$ & 94,13 & 95,63 & $94,88 a$ \\
\hline Colhedora convencional a $6 \mathrm{~km} \mathrm{~h}^{-1}$ & 96,25 & 96,75 & $96,50 a$ \\
\hline Colheita manual & 97,13 & 97,88 & $97,51 a$ \\
\hline Média & $95,86 \mathrm{~A}$ & $95,96 \mathrm{~A}$ & \\
\hline CV (\%) parcela & & 1,57 & \\
\hline CV (\%) subparcela & & 1,27 & \\
\hline
\end{tabular}

*Médias seguidas por letras distintas maiúsculas, nas linhas, e minúsculas, nas colunas, diferem significativamente entre si, a 5\% de probabilidade pelo teste de Tukey.
Como as velocidades testadas para cada máquina se encontravam em faixas adequadas de operação, sua variação não causou danos significativos na germinação, concordando com as afirmações de HERBEK \& BITZER (1997). Esses autores afirmam que as perdas de germinação, em geral, são menores para combinações de velocidade e rotação dentro dessa faixa de operação. VIEIRA et al. (2006), estudando a qualidade de sementes de soja colhidas por uma colhedora de rotor axial simples, também não encontraram efeito da velocidade na germinação.

Destaca-se que a umidade da semente durante a colheita estava dentro da faixa ideal, o que minimiza a influência na germinação. Resultados diferentes poderiam ocorrer em condições mais adversas de umidade na colheita, principalmente em favor das colhedoras axiais. Os coeficientes de variação encontrados foram adequados para todas as variáveis analisadas neste trabalho.

\section{CONCLUSÕES}

O emprego das colhedoras com sistemas de trilha tangencial e axial não provocou diferenças no índice de velocidade de emergência, no vigor e na germinação das sementes de soja, indicando que, desde que convenientemente reguladas, não provocam diferenças nos valores desses parâmetros. No entanto, com relação à injúria mecânica, a colhedora axial, a 6 e $8 \mathrm{~km} \mathrm{~h}^{-1}$, mostrou-se superior à convencional. $\mathrm{O}$ armazenamento reduziu o vigor das sementes colhidas. O incremento da velocidade de deslocamento, dentro dos parâmetros recomendados pelo fabricante, não alterou a qualidade das sementes. As colhedoras mecânicas não alteraram a qualidade das sementes, com exceção do parâmetro injúria mecânica, que foi menor na colheita manual.

\section{REFERÊNCIAS}

BASRA, A.S. Seed quality: basic mechanisms and agricultural implications. New York: Food Products, 1994. 389p.

BRASIL. Ministério da Agricultura. Regras para análise de sementes. Brasília: DNDV/CLAV, 1992. 365p.

COSTA, N.P. et al. Qualidade fisiológica, física e sanitária de sementes de soja produzidas no Brasil. Revista Brasileira de Sementes, Londrina, v.25, n.1, p.128-132, 2003. Disponível em: <http:// www.scielo.br/scielo.php?script=sci_arttext $\&$ pid=S0101$31222003000100020 \& \operatorname{lng}=$ en\&nrm=iso $>$. Doi: $10.1590 /$ S010131222003000100020 .

COSTA, N.P. et al. Perfil dos aspectos físicos, fisiológicos e químicos de sementes de soja produzidas em seis regiões do 
Brasil. Revista Brasileira de Sementes, Brasília, v.27, n.2, p.172-181, 2005. Disponível em: <http://www.scielo.br/ scielo.php? script=sci_arttext\&pid=S 0101 31222005000200025\&lng=en\&nrm=iso>. Doi: $10.1590 /$ S0101-31222005000200025.

COSTA, N.P. et al. Efeito da colheita mecânica da soja nas características físicas, fisiológicas e químicas das sementes em três Estados do Brasil. Revista Brasileira de Sementes, Londrina, v.23, n.1, p.140-145, 2001.

COSTA, N.P. et al. Efeito da colheita mecânica sobre a qualidade da semente de soja. Revista Brasileira de Sementes, Campinas, v.18, n.2, p.232-237, 1996

EMPRESA BRASILEIRA DE PESQUISA AGROPECUARIA Tecnologias de produção de soja. Londrina: Embrapa Soja, 2005. 224p. (Sistemas de produção/EMBRAPA Soja, n.5).

FRANÇA NETO, J.B.; HENNING, A.A. Qualidade fisiológica e sanitária de semente de soja. Londrina: Embrapa Soja, 1984. 39p. (Circular Técnica, 9)

HERBEK, J.H.; BITZER, M.J. Soybean production in Kentucky: harvest, drying, storage and marketing. Lexington: University of Kentucky, College of Agriculture, 1997. p.1-5.

MAGUIRE, J.D. Speed of germination-aid in selection and evaluation for seedling emergence and vigor. Crop Science, Madison, v.2, n.1, p.176-177, 1962.
MARCONDES, M.C. et al. Danos mecânicos e qualidade fisiológica de semente de soja colhida pelo sistema convencional e axial. Revista Brasileira de Sementes, Brasília, v.27, n.2, p.125-129, 2005. Disponível em: <http://www.scielo.br/ scielo.php ? script =s ci_art text \& pid = S 0101 $31222005000200018 \& \operatorname{lng}=$ en $\&$ nrm=iso>. Doi: $10.1590 /$ S0101-31222005000200018.

PAIVA, L.E. et al. Beneficiamento de sementes de milho colhidas mecanicamente em espigas: efeitos sobre danos mecânicos e qualidade fisiológica. Ciência e Agrotecnologia, Lavras, v.24, n.4, p.846-856, 2000.

VAUGHAN, C.E. Quality assurance techniques - the Clorox test. In: SHORT COURSE FOR SEEDSMEN, 1982, Mississipi. Proceedings... Mississipi: State College, 1982. p.117-118.

VEJASIT, A.; SALOKHE, V.M. Studies on machine crop parameters of an axial flow thresher for threshing soybean. Agriculture Engineering International, Texas, v.6, n.1, p.1-12, 2004

VIEIRA, B.G.T.L. et al. Qualidade física e fisiológica de sementes de soja colhida com sistema de trilha axial sob diferentes velocidades de operação e rotações do cilindro trilhador. Engenharia Agrícola, Jaboticabal, v.26, n.2, p.478-482, 2006. Disponível em: <http:// www.scielo.br/scielo.php?script=sci_arttext\&pid=S0100 69162006000200016\&lng=en\&nrm=iso>. Doi: 10.1590/S010069162006000200016 . 